\title{
Struktur dari Garis
}

\author{
Denik Agustito \\ Universitas Sarjanawiyata Tamansiswa \\ agustito@ustjogja.ac.id
}

\begin{abstract}
ABSTRAK
Dalam tulisan ini, sebuah garis $L$ pertama kali dikontruksi melalui pemetaan bijektif $f: L \rightarrow \mathbb{R}$. Pemetaan bijektif $f$ menjadikan $L$ menjadi sebuah ruang topologi, memberikan struktur aljabarik padanya yaitu berupa lapangan dan memberikan sebuah struktur relasional urutan yaitu berupa urutan. Kemudian sifat geometri dari garis diawali dengan mendefinisikan sebuah norma pada $L$ hingga diperoleh bahwa garis $L$ tersebut dapat dikonstruksi melalui sekurang-kurangnya dua titik yang berbeda padanya.
\end{abstract}

Kata kunci: aljabarik, bijektif, garis, norma, topologi, urutan.

\section{ABSTRACT}

In this paper, an $L$ line is first constructed through an objective mapping $f: L \rightarrow \mathbb{R}$. The objective mapping $f$ makes $L$ become a topological space, gives it an algebraic structure in the form of a field and provides a sequence of relational structures in the form of sequences. Then the geometrical nature of the line begins by defining a norm at $L$ until it is obtained that the $L$ line can be constructed through at least two different points on it.

Keywords: algebra, bijective, lines, norms, topology, sequence. 


\section{PENDAHULUAN}

Ide dari tulisan ini berawal dari buku (Umble R N, Han Z, 2015) mengenai sifat-sifat dari garis menurut aksioma dari geometri bidang Euclidean. Dalam buku tersebut, sebuah garis diberikan secara intuitif (tidak secara formal); artinya dengan mengacu pada Postulat Insidensi dari geometri bidang Euclidean, sebuah garis adalah himpunan dari titik, dan melalui setiap dua titik yang berbeda yaitu $A$ dan $B$, terdapat tepat satu garis $l$, dan dinotasikan dengan $l=\overleftrightarrow{A B}$. Kemudian dari Postulat Jarak pada geometri bidang Euclidean mengatakan bahwa jika diberikan dua buah titik $A$ dan $B$ maka terdapat secara tunggal bilangan real yang dinotasikan dengan $|A B|$, dan katakan $|A B|$ ini sebagai jarak antara $A$ dan $B$.

Selanjutnya gagasan mengenai jarak di antara titik $A$ dan $B$ akan diterapkan pada sebuah garis $l$ yang dikenal dengan Postulat Penggaris yang mengatakan bahwa jika diberikan garis $l$ maka terdapat pemetaan bijektif $f: l \rightarrow \mathbb{R}$ yang sifatnya $|A B|=|f(A)-f(B)|$ untuk setiap titik $A$ dan $B$ pada $l$. Dengan melihat pemetaan bijektif $f: l \rightarrow \mathbb{R}$ pada Postulat Penggaris, penulis akan mengkaji struktur pada $l$ yang serupa dengan struktur pada $\mathbb{R}$. Karena $\mathbb{R}$ memiliki struktur topologis yaitu berupa ruang metrik, memiliki struktur aljabarik berupa lapangan dan struktur relasional urutan berupa rantai, maka dalam tulisan ini akan dikonstruksi $l$ yang memiliki struktur topologis berupa ruang metrik, struktur aljabarik berupa lapangan dan struktur relasional urutan berupa rantai serta mengkonstruksi $l$ dari dua buah titik yang berbeda melalui struktur-struktur yang telah dipunyai padanya.

\section{STRUKTUR TOPOLOGIS, STRUKTUR ALJABARIK, DAN STRUKTUR RELASIONAL URUTAN PADA GARIS}

Langkah pertama pada bagian ini adalah memandang himpunan tak-kosong $L$ sebagai ruang topologi, yaitu secara spesifik sebagai ruang metrik dimana metriknya akan dibangkitkan melalui pemetaan bijektif $f: L \rightarrow \mathbb{R}$. Dengan mengacu pada Hirali \& Vasudeva (2006), pengertian ruang metrik akan diberikan sebagai berikut.

\section{Definisi 1.1.}

Pada himpunan tak-kosong $X$, pemetaan $d: X \times X \rightarrow \mathbb{R}$ dikatakan metrik pada $X$ jika memenuhi sifat berikut:

(M1). $d(x, y) \geq 0$ untuk setiap $x, y \in X$.

(M2). $d(x, y)=0$ jika dan hanya jika $x=y$.

(M3). $d(x, y)=d(y, x)$ untuk setiap $x, y \in X$.

(M4). $d(x, y) \leq d(x, z)+d(z, y)$ untuk setiap $x, y, z \in X$.

\section{Teorema 1.2.}

Diberikan himpunan tak-kosong $L$ dan pemetaan bijekif $f: L \rightarrow \mathbb{R}$. Pemetaan $d_{L}: L \times L \rightarrow \mathbb{R}$ yang didefinisikan dengan $d_{L}(x, y)=d_{\mathbb{R}}(f(x), f(y))=|f(x)-f(y)|$ mendefinisikan sebuah metrik pada $L$. 


\section{Bukti:}

Karena $|f(x)-f(y)|$ didefinisikan melalui metrik pada $\mathbb{R}$ yaitu $d_{\mathbb{R}}(a, b)=|a-b|$, jelas $d_{L}(x, y)=|f(x)-f(y)|$ mendefinisikan sebuah metrik pada $L$.

Karena $d_{L}$ adalah metrik pada $L$, jelas diperoleh ruang metrik $\left(L, d_{L}\right)$. Metrik $d_{L}$ pada $L$ dinamakan metrik yang dibangkitkan oleh pemetaan bijektif $f: L \rightarrow \mathbb{R}$. Selanjutnya akan diberikan suatu sifat bahwa pemetaan bijektif membangkitkan sebuah homeomoerfisma di antara ruang metrik $f_{*}:\left(L, d_{L}\right) \rightarrow\left(\mathbb{R}, d_{\mathbb{R}}\right)$. Homeomorfisma adalah sebuah pemetaan bijektif kontinu dan inversnya juga kontinu di antara dua buah ruang topologi (secara khusus di antara ruang metrik). Mengacu dari [4], pemetaan kontinu didefinisikan sebagai berikut: Pemetaan $f:\left(X, d_{X}\right) \rightarrow\left(Y, d_{Y}\right)$ dikatakan kontinu jika diberikan sembarang $x \in X$ dan sembarang barisan $\left\{x_{n}\right\}_{n \in \mathbb{N}}$ konvergen ke $x$ maka barisan $\left\{f\left(x_{n}\right)\right\}_{n \in \mathbb{N}}$ konvergen ke $f(x)$.

\section{Sifat 1.3.}

Pemetaan bijektif $f: L \rightarrow \mathbb{R}$ membangkitkan sebuah homeomorfisma $f:\left(L, d_{L}\right) \rightarrow\left(\mathbb{R}, d_{\mathbb{R}}\right)$.

Bukti:

Ambil sembarang barisan $\left\{x_{n}\right\}_{n \in \mathbb{N}}$ dalam $L$ yang konvergen ke $x \in L$. Jelas $\forall \varepsilon>0 \exists N \in \mathbb{N} \ni$ $n \geq N \Rightarrow d_{L}\left(x_{n}, x\right)=d_{\mathbb{R}}\left(f\left(x_{n}\right), f(x)\right)<\varepsilon$. Jadi barisan $\left\{f\left(x_{n}\right)\right\}_{n \in \mathbb{N}}$ dalam $\mathbb{R}$ konvergen di $f(x) \in \mathbb{R}$ dan akibatnya $f:\left(L, d_{L}\right) \rightarrow\left(\mathbb{R}, d_{\mathbb{R}}\right)$ adalah kontinu. Karena $f: L \rightarrow \mathbb{R}$ adalah pemetaan bijektif, jelas $f^{-1}: \mathbb{R} \rightarrow L$ juga bijektif dan dibuktikan bahwa $f^{-1}: \mathbb{R} \rightarrow L$ juga kontinu. Ambil sembarang barisan $\left\{x_{n}\right\}_{n \in \mathbb{N}}$ dalam $\mathbb{R}$ yang konvergen $x \in \mathbb{R}$. Karena $f$ adalah bijektif, jelas $\forall \varepsilon>0 \exists N \in \mathbb{N} \ni n \geq N \Rightarrow d_{\mathbb{R}}\left(x_{n}, x\right)=d_{\mathbb{R}}\left(f\left(f^{-1}\left(x_{n}\right)\right)-f\left(f^{-1}(x)\right)\right)<\varepsilon$. Jadi barisan $f^{-1}\left(x_{n}\right)_{n \in \mathbb{N}}$ dalam $L$ konvergen ke $f^{-1}(x) \in L$ dan akibatnya $f^{-1}: \mathbb{R} \rightarrow L$ adalah kontinu. Dengan demikian $f:\left(L, d_{L}\right) \rightarrow\left(\mathbb{R}, d_{\mathbb{R}}\right)$ adalah homoeomorfisma.

Jika dua terdapat sebuah homeomorfisma di antara dua ruang topologi (secara khusus ruang metrik), maka kedua ruang topologi (secara khusus ruang metrik) tersebut dikatakan homeomorfik; dengan kata lain, ruang $X$ homeomorfik dengan ruang $Y$ jika terdapat homoemorfisma $f: X \rightarrow Y$. Dalam tulisan ini, jika ruang topologi (secara khusus ruang metrik) yang homeomorfik dengan $\left(\mathbb{R}, d_{\mathbb{R}}\right)$ dinamakan Ruang Garis.

\section{Contoh 1.4.}

Pada Parabola $P=\left\{\left(r, r^{2}\right): r \in \mathbb{R}\right\}$ terdapat pemetaan bijektif $f: P \rightarrow \mathbb{R}$ yang didefinisikan dengan $f\left(\left(r, r^{2}\right)\right)=r$. Karena pemetaan bijektif $f: P \rightarrow \mathbb{R}$ membangkitkan homeomorfisma $f:\left(P, d_{P}\right) \rightarrow\left(\mathbb{R}, d_{\mathbb{R}}\right)$, jelas $P$ homeomorfik dengan $\mathbb{R}$ dan akibatnya parabola $P=$ $\left\{\left(r, r^{2}\right): r \in \mathbb{R}\right\}$ adalah Ruang Garis.

Selanjutnya akan didefinisikan sebuah operasi penjumlahan, pengurangan, perkalian dan pembagian dalam Ruang Garis $\left(L, d_{L}\right)$ dengan maksud untuk memandang Ruang Garis $\left(L, d_{L}\right)$ memiliki struktur aljabar.

\section{Sifat 1.5.}


Diberikan Ruang Garis $\left(L, d_{L}\right)$. Pemetaan $+_{L}: L \times L \rightarrow L$ yang didefinisikan dengan $+_{L}((a, b))=f^{-1}(f(a)+f(b))$ dan pemetaan ${ }_{L}: L \times L \rightarrow L$ yang didefinisikan dengan ${ }_{\cdot L}((a, b))=f^{-1}(f(a) \cdot f(b))$ mendefinisikan operasi biner $L$.

Karena $+_{L}$ dan $\cdot_{L}$ adalah operasi biner pada $L$, selanjutnya akan dikonstruksi bahwa Ruang Garis $\left(L, d_{L}\right)$ membentuk sebuah lapangan.

\section{Teorema 1.6.}

$\left(L,+_{L}, \cdot L\right)$ membentuk lapangan.

Bukti:

Elemen nol dalam $L$ adalah $0_{L}=f^{-1}(0)$, elemen satuan dalam $L$ adalah $1_{L}=f^{-1}(1)$, invers dari $a \in L$ terhadap $+_{L}$ adalah $-a \stackrel{\text { def }}{=} f^{-1}(-f(a))$ dan invers dari $a \in L$ dengan $a \neq 0$ terhadap terhadap $\cdot_{L}$ adalah $\frac{1}{a} \stackrel{\text { def }}{=} f^{-1}\left(\frac{1}{f(a)}\right)$. Ini semua memenuhi aksioma lapangan seperti ada pada Fraleigh (1976).

\section{Contoh 1.7.}

Pandang Ruang Garis berupa parabola $P=\left\{\left(r, r^{2}\right): r \in \mathbb{R}\right\}$. Parabola $P=\left\{\left(r, r^{2}\right): r \in \mathbb{R}\right\}$ ini membentuk sebuah lapangan dimana operasi penjumlahan dan perkaliannya didefinisikan seperti pada Teorema 1.6. Jika $(-1,1),(2,4) \in P$ maka

$$
(-1,1)+{ }_{P}(2,4)=f^{-1}(f((-1,1))+f((2,4)))=f^{-1}(-1+2)=f^{-1}(1)=(1,1) .
$$

Jadi Ruang Garis berupa Parabola $P=\left\{\left(r, r^{2}\right): r \in \mathbb{R}\right\}$ berlaku penjumlahan $(-1,1)+{ }_{P}(2,4)=(1,1)$.

Lapangan pada Teorema 1.6 dinamakan Lapangan Garis. Operasi pengurangan pada Lapangan Garis didefinisikan dengan $a-{ }_{L} b=a+{ }_{L}(-b)$ dan operasi pembagian pada Lapangan Garis didefinisikan dengan $\frac{a}{b}=a_{\cdot L} \frac{1}{b}$ untuk $b \neq 0_{L}$. Jika Sifat 1.3 mengatakan pemetaan bijektif $f: L \rightarrow \mathbb{R}$ membangkitkan ekuivalensi topologis atau homoemorfisma $f:\left(L, d_{L}\right) \rightarrow\left(\mathbb{R}, d_{\mathbb{R}}\right)$, maka selanjutnya akan diberikan sifat bahwa fungsi bijektif $f: L \rightarrow \mathbb{R}$ akan membangkitkan sebuah ekuivalensi aljabarik atau isomorfisma lapangan $f_{*}:\left(L,+_{L}, \cdot L\right) \rightarrow(\mathbb{R},+,$.$) .$

\section{Sifat 1.8.}

Pemetaan bijektif $f: L \rightarrow \mathbb{R}$ membangkitkan sebuah isomorfisma $f_{*}:\left(L,+_{L}, \cdot_{L}\right) \rightarrow(\mathbb{R},+,$.$) .$ Bukti:

Definisikan pemetaan $f_{*}:\left(L,+_{L}, \cdot{ }_{L}\right) \rightarrow(\mathbb{R},+,$.$) dengan f_{*}(x)=f(x)$. Karena $f$ bijektif, selanjutnya akan dibuktikan bahwa $f_{*}$ adalah homomorfisma ring. Sembarang $x, y \in L$ berlaku

$$
f_{*}\left(x+{ }_{L} y\right)=f\left(x+{ }_{L} y\right)=f\left(f^{-1}(f(x)+f(y))\right)=f(x)+f(y)=f_{*}(x)+f_{*}(y)
$$

dan

$$
f_{*}\left(x_{\cdot L} y\right)=f\left(x_{\cdot L} y\right)=f\left(f^{-1}(f(x) \cdot f(y))\right)=f(x) \cdot f(y)=f_{*}(x) \cdot f_{*}(y) .
$$

Jadi $f_{*}:\left(L,+_{L}, \cdot L\right) \rightarrow(\mathbb{R},+,$.$) adalah isomorfisma.$ 
Karena terdapat isomorfisma di antara lapangan yaitu $f_{*}:\left(L,+_{L}, \cdot L\right) \rightarrow(\mathbb{R},+,$.$) , maka$ Lapangan Garis dikatakan isomorfik dengan Lapangan Bilangan Real. Akibatnya semua sifatsifat aljabarik pada $\left(L,+_{L}, \cdot L\right)$ adalah sama dengan sifat-sifat aljabarik pada $(\mathbb{R},+,$.$) . Sifat-$ sifat aljabarik pada $(\mathbb{R},+$, . ) dapat ditemukan dalam (Bartle. R G, Sherbert. D R, (2001)).

Kemudian akan dikonstruksi struktur relasional terurut pada Ruang Garis $\left(L, d_{L}\right)$. Dengan mengacu pada (Gratzer G, (2010)), gagasan mengenai Poset (himpunan terturut sebagian) dan Rantai (himpunan terurut total) akan diberikan sebagai berikut.

\section{Definisi 1.9.}

Diberikan himpunan tak-kosong $A$, relasi urutan $\preccurlyeq$ pada $A$ dikatakan terurut sebagian jika diberikan $a, b, c \in A$.

(P1). $a \leqslant a$.

(P2). Jika $a \leqslant b$ dan $b \leqslant a$ maka $a=b$.

(P3). Jika $a \preccurlyeq b$ dan $b \preccurlyeq c$ maka $a \preccurlyeq c$.

Pada Definisi 1.9 , pasangan $(A, \preccurlyeq)$ dinamakan Poset (Partially Ordered Set) atau himpunan terurut sebagian. Poset $(A, \preccurlyeq)$ dikatakan rantai jika diberikan $a, b \in A$ maka berlaku tepat satu $a \leqslant b$ atau $a=b$ atau $a \geqslant b$. Langkah pertama untuk mengkonstruksi urutan pada Ruang Garis $\left(L, d_{L}\right)$ dengan cara mendefinisikan sebuah himpunan elemen positif dimana gagasan tersebut mengikuti dari Bartle \& Sherbert (2001) mengenai sifat urutan dari $\mathbb{R}$.

\section{Lemma 1.10.}

Diberikan Lapangan Garis $\left(L,+_{L}, \cdot L\right.$. Terdapat sebuah himpunan tak-kosong $P \subset L$ yang memenuhi sifat berikut:

(U1). $\forall a, b \in L, a+{ }_{L} b \in P$.

(U2). $\forall a, b \in L, a_{\cdot L} b \in P$.

(U3). $\forall a \in L, a \in P$ atau $a=0_{L}$ atau $-a \in P$. (Hukum Trikotomi pada Garis)

Bukti:

Dengan memilih himpunan $P=\{a \in L: f(a)>0\}$ selanjutnya dengan mudah dibuktikan bahwa $P$ memenuhi sifat U1, U2, dan U3.

\section{Notasi 1.11.}

Diberikan Lapangan Garis $\left(L,+_{L}, \cdot L\right)$ dan $a \in L$.

(i). Jika $a \in P$ maka akan ditulis $a>_{L} 0_{L}$.

(ii). Jika $a \in P \cup\left\{0_{L}\right\}$ maka akan ditulis $a \geq_{L} 0_{L}$.

(iii). Jika $-a \in P$ maka akan ditulis $a<_{L} 0_{L}$.

(iv). Jika $-a \in P \cup\left\{0_{L}\right\}$ maka akan ditulis $a \leq_{L} 0_{L}$.

Dimana $P \cup\left\{0_{L}\right\}$ juga dapat dinyatan sebagai himpunan $P \bigcup\left\{0_{L}\right\}=\{a \in L: f(a) \geq 0\}$. 


\section{Definisi 1.12.}

Diberikan Lapangan Garis $\left(L,+_{L}, \cdot L\right)$ dan $a, b \in L$.

(i). $\quad a>_{L} b \stackrel{\text { def }}{\Leftrightarrow} a-{ }_{L} b \in P$.

(ii). $\quad a \geq_{L} b \stackrel{\text { def }}{\Leftrightarrow} a-{ }_{L} b \in P \bigcup\left\{0_{L}\right\}$.

Dengan berbekal Lemma 1.10, Notasi 1.11, dan Definisi 1.12, akan dibuktikan bahwa Lapangan Garis $\left(L,+_{L}, \cdot L\right)$ bersama dengan relasi $\geq$ membentuk Rantai.

\section{Sifat 1.13.}

Diberikan Lapangan Garis $\left(L,+_{L}, \cdot L\right)$.

(i). $\forall a \in L, a \geq_{L} a$ (Relasi $\geq_{L}$ bersifat refleksif)

(ii). $\forall a, b \in L, a \geq_{L} b$ dan $b \geq_{L} a \Rightarrow a=b$ (Relasi $\geq_{L}$ bersifat anti-simetrik)

(iii). $\forall a, b, c \in L, a \geq_{L} b$ dan $b \geq_{L} c \Rightarrow a \geq_{L} c \quad$ (Relasi $\geq_{L}$ bersifat transitif)

(iv). $\forall a, b \in L$ maka berlaku salah satu $a \geq_{L} b$ atau $a=b$ atau $a \leq_{L} b$.

Bukti:

(i). Setiap $a \in L$, jelas berlaku $a-{ }_{L} a=0_{L} \in P \bigcup\left\{0_{L}\right\}$. Akibatnya $\forall a \in L, a \geq_{L} a$.

(ii). (Pembuktian dengan kontraposisi).

Setiap $a, b \in L$ yang sifatnya $a \neq b$, jelas berlaku $a-{ }_{L} b \neq 0$. Berdasarkan Hukum Trikotomi pada Garis, jelas $a-{ }_{L} b>_{L} 0_{L}$ atau $a-{ }_{L} b<_{L} 0_{L}$.

Karena $a-{ }_{L} b>_{L} 0_{L}$, Jelas berlaku $a>_{L} b$. Begitu juga jika $a-{ }_{L} b<_{L} 0_{L}$, maka $a<_{L} b$. Jadi terbukti $a>_{L} b$ atau $a<_{L} b$.

Jadi $\forall a, b \in L, a \geq_{L} b$ dan $b \geq_{L} a \Rightarrow a=b$.

(iii). Jika $a \geq_{L} b$ dan $b \geq_{L} c$ maka $a-{ }_{L} b \in P \cup\left\{0_{L}\right\}$ dan $b-{ }_{L} c \in P \cup\left\{0_{L}\right\}$. Jelas $a-{ }_{L} c=$ $\left(a-{ }_{L} b\right)+{ }_{L}\left(b-{ }_{L} c\right) \in P \cup\left\{0_{L}\right\}$. Akibatnya $a \geq_{L} c . \quad$ Jadi $\quad \forall a, b, c \in L, a \geq_{L} b \quad$ dan $b \geq_{L} c \Rightarrow a \geq_{L} c$.

(iv). Karena $a, b \in L$, jelas $a-{ }_{L} b \in L$, jelas berdasarkan Hukum Trikotomi Garis berlaku $a-{ }_{L} b>_{L} 0_{L}$ atau $a-{ }_{L} b=0_{L}$ atau $a-{ }_{L} b<_{L} 0_{L}$. Akibatnya berlaku $a-{ }_{L} b \geq_{L} 0_{L}$ atau $a-{ }_{L} b=0_{L}$ atau $a-{ }_{L} b \leq_{L} 0_{L}$. Karena $a-{ }_{L} b \geq_{L} 0_{L}$ atau $a-{ }_{L} b=0_{L}$ atau $a-{ }_{L} b \leq_{L} 0_{L}$, jelas berlaku $a \geq_{L} b$ atau $a=b$ atau $a \leq_{L} b$.

Jadi untuk setiap $a, b \in L$, berlaku $a \geq_{L} b$ atau $a=b$ atau $a \leq_{L} b$.

Lapangan garis $\left(L,+_{L}, \cdot L\right)$ yang dilengkapi dengan relasi $\geq_{L}$ dan memenuhi sifat pada Sifat 1.13 dinamakan Rantai Garis kemudian Rantai Garis akan dinotasikan dengan $\left(L, \geq_{L}\right)$. Jika pemetaan bijektif $f: L \rightarrow \mathbb{R}$ membangkitkan homeomorfisma dan isomorfisma, maka pemetaan bijektif tersebut juga akan membangkitkan isomorfism di anatara rantai atau isoton rantai. Isoton rantai adalah isomorfisma poset di antara dua buah rantai.

\section{Definisi 1.14.}

Pemetaan $f:\left(X, \preccurlyeq_{X}\right) \rightarrow\left(Y, \preccurlyeq_{Y}\right)$ di antara poset dikatakan monoton jika untuk setiap $a, b \in X$ yang sifatnya $a \preccurlyeq_{X} b$ maka $f(a) \preccurlyeq_{Y} f(b)$. Pemetaan $f:\left(X, \preccurlyeq_{X}\right) \rightarrow\left(Y, \preccurlyeq_{Y}\right)$ dikatakan isoton jika $f$ monoton dan bijektif serta inversnya $f^{-1}$ juga monoton. 


\section{Sifat 1.15.}

Pemetaan bijektif $f: L \rightarrow \mathbb{R}$ membangkitkan sebuah isoton $f_{*}:\left(L, \geq_{L}\right) \rightarrow(\mathbb{R}, \geq)$.

Bukti:

Sembarang $a, b \in L$ yang bersifat $a \geq_{L} b$ mengakibatkan $a-{ }_{L} b \in P \cup\{0\}$. Jelas diperoleh bahwa $f(a)-f(b) \geq 0$ dan akibatnya $f(a) \geq f(b)$. Ini artinya $f_{*}$ adalah monoton. Dilain pihak juga $f_{*}$ adalah bijektif. Ini mudah untuk membuktikan bahwa invers dari $f_{*}$ yaitu $f_{*}^{-1}$ juga monoton. Jadi $f_{*}:\left(L, \geq_{L}\right) \rightarrow(\mathbb{R}, \geq)$ adalah isoton.

\section{GEOMETRI PADA GARIS}

Pada bagian sebelumnya, jelas kita dapat mengatakan bahwa pada sebuah himpunan $L$, pemetaan bijektif $f: L \rightarrow \mathbb{R}$ membangkitkan sebuah ruang metrik $\left(L, d_{L}\right)$ yang dinamakan dengan Ruang Garis, lapangan $\left(L,+_{L}, \cdot L\right)$ yang dinamakan dengan Lapangan Garis dan rantai $\left(L, \geq_{L}\right)$ yang dinamakan dengan rantai garis. Bagian ini akan dikaji sifat-sifat geometrik dari Rantai Garis dengan terlebih dahulu memperkenalkan gagasan norma pada Rantai Garis $\left(L, \geq_{L}\right)$ yaitu sebagai berikut.

\section{Definisi 1.16.}

Diberikan sebuah Rantai Garis $\left(L, \geq_{L}\right)$ dan $a \in L$. Norma dari $a$ ditulis dengan $\|a\|$ dan didefinisikan sebagai $\|a\|=|f(a)|$.

\section{Lemma 1.17.}

Diberikan sebuah Rantai Garis $\left(L, \geq_{L}\right)$ dan $a, b \in L$.

(i). $\|a\|=0$ jika dan hanya jika $a=0_{L}$.

(ii). $\left\|a_{\cdot L} b\right\|=\|a\| .\|b\|$.

(iii). $\|a\|=\|-a\|$.

(iv). $\left\|a+{ }_{L} b\right\| \leq\|a\|+\|b\|$.

Bukti:

(i). Jika $\|a\|=0$ maka $|f(a)|=0$ dan akibatnya $f(a)=0=f(0)$. Karena $f$ bijektif, jadi $a=0_{L}$. Kebalikannya, jika $a=0_{L}$, maka diperoleh $\|a\|=\left\|0_{L}\right\|=\left|f\left(0_{L}\right)\right|=|0|=0$. Jadi $\|a\|=0$.

(ii). $\quad\left\|a_{\cdot} b\right\|=\left\|f^{-1}(f(a) \cdot f(b))\right\|=\left|f\left(f^{-1}(f(a) \cdot f(b))\right)\right|=|f(a) \cdot f(b)|=$ $|f(a)\|f(b) \mid=\| a\|\|$.$b \| .$

(iii). $\|-a\|=\left\|f^{-1}(-f(a))\right\|=\left|f\left(f^{-1}(-f(a))\right)\right|=|-f(a)|=|f(a)|=\|a\|$.

(iv). $\left\|a+_{L} b\right\|=\left\|f^{-1}(f(a)+f(b))\right\|=|f(a)+f(b)| \leq|f(a)|+|f(b)|=\|a\|+\|b\|$.

Setelah mendefinisikan norma pada Rantai Garis, selanjutnya adalah mendefinisikan jarak di antara dua elemen pada Rantai Garis yang dibangkitkan memlalui norma di atas.

\section{Definisi 1.18.}

Diberikan sebuah Rantai Garis $\left(L, \geq_{L}\right)$ dan $a, b \in L$. Jarak antara $a$ dan $b$ didefinisikan dengan $d_{L}(a, b)=\left\|a-{ }_{L} b\right\|$. 
Diberikan juga sebuah sifat bahwa jarak yang didefinisikan dalam Definisi 1.18 juga kompatibel dengan jarak yang didefinisikan pada Teorema 1.2.

\section{Sifat 1.19.}

Jarak $d_{L}(a, b)=\left\|a-{ }_{L} b\right\|$ kompatibel dengan jarak yang diberikan dalam Teorema 1.2.

Bukti:

Jelas bahwa $\left\|a-{ }_{L} b\right\|=\left\|f^{-1}(f(a)-f(b))\right\|=|f(a)-f(b)|=d_{L}(a, b)$. Ini artinya $d_{L}(a, b)=\left\|a-{ }_{L} b\right\|$ kompatibel dengan jarak yang diberikan dalam Teorema 1.2.

Mengacu pada Umble \& Han (2015), gagasan ke-di antara-an titik di antara dua titik dalam sebuah garis akan dikenakan juga pada sebuah Rantai Garis yaitu sebagai berikut.

\section{Definisi 1.20.}

Diberikan sebuah Rantai Garis $\left(L, \geq_{L}\right)$ dan $a, b \in L$. Elemen $c \in L$ dikatakan elemen di antara $a$ dan $b$ dan ditulis $a-c-b$ jika $d_{L}(a, b)=d_{L}(a, c)+d_{L}(c, b)$.

Dari gagasan mengenai ke-di antara-an memberikan sebuah motivasi untuk mendefinisikan ruas garis, sinar garis, dan garis.

\section{Definisi 1.21.}

Diberikan sebuah Rantai Garis $\left(L, \geq_{L}\right)$ dan $a, b \in L$.

(i). Ruas garis yang memuat titik $a$ dan $b$ adalah himpunan $\overline{a b}=\{c \in L: a-c-b\}$.

(ii). Sinar positif yang memuat titik $a$ dan $b$ adalah himpunan $\overrightarrow{a b}=\{c \in L: a-b-c\}$.

(iii). Sinar negatif yang memuat titik $a$ dan $b$ adalah himpunan $\overleftarrow{a b}=\{c \in L: c-a-b\}$.

(iv). Garis yang memuat titik $a$ dan $b$ adalah himpunan $\overleftrightarrow{a b}=\overleftrightarrow{a b} \cup \overline{a b} \cup \overrightarrow{a b} \cup\{a, b\}$.

Keterhubungan garis yang memuat titik $a$ dan $b$ yang dinotasikan dengan $\overleftrightarrow{a b}$ dengan Rantai Garis diberikan pada sifat berikut.

\section{Sifat 1.22.}

Jika diberikan sebuah Rantai Garis $\left(L, \geq_{L}\right)$ dan $a, b \in L$ dengan $a \leq_{L} b$ maka $L=\overleftrightarrow{a b}$.

Bukti:

Karena $a, b \in L$ jelas $\overleftrightarrow{a b} \subseteq L$. Sembarang $x \in L$ dan dengan Sifat 1.13 (iv) berlaku tepat satu $a \leq_{L} x$ atau $a=x$ atau $a \geq_{L} x$. Jika $a \leq_{L} x$ maka berlaku tepat satu $b \leq_{L} x$ atau $b=x$ atau $b \geq_{L} x$. Jika $b \leq_{L} x$ maka $x \in \overrightarrow{a b}$, jika $b=x$ maka $x \in\{a, b\}$ dan jika $b \geq_{L} x$ maka $x \in \overline{a b}$, akibatnya $x \in \overleftrightarrow{a b}$. Jika $a=x$ maka $x \in\{a, b\}$ dan akibatnya $x \in \overleftrightarrow{a b}$. Jika $a \geq_{L} x$ maka $x \in \overleftarrow{a b}$ dan akibatnya $x \in \overleftrightarrow{a b}$. Jadi jika $x \in L$ maka $x \in \overleftrightarrow{a b}$ dan akibatnya $L \subseteq \overleftrightarrow{a b}$. Karena $\overleftrightarrow{a b} \subseteq L$ dan $L \subseteq \overleftrightarrow{a b}$, jelas $L=\overleftrightarrow{a b}$

Sifat 1.22 ini mengatakan bahwa Rantai Garis $\left(L, \geq_{L}\right)$ yang memuai titik $a$ dan $b$ tidak lain adalah garis $\overleftrightarrow{a b}$ dan ditulis dengan $L=\overleftrightarrow{a b}$. 


\section{KESIMPULAN}

Kesimpulan dari tulisan ini adalah sebuah Garis $L$ dapat dibentuk melalui sebuah pemetaan bijektif $f: L \rightarrow \mathbb{R}$. Karena $\mathbb{R}$ membentuk ruang topologi (secara khusus adalah ruang metrik) maka pemetaan bijektif $f: L \rightarrow \mathbb{R}$ menjadikan Garis $L$ menjadi ruang topologi (secara khusus ruang metrik) dan dinamakan dengan Ruang Garis. Karena $\mathbb{R}$ membentuk lapangan maka pemetaan bijektif $f: L \rightarrow \mathbb{R}$ menjadikan Garis $L$ memiliki struktur aljabarik yaitu lapangan dan dinamakan dengan Lapangan Garis. Karena $\mathbb{R}$ membentuk rantai terhadap relasi urutan maka pemetaan bijektif $f: L \rightarrow \mathbb{R}$ menjadikan Garis $L$ menjadi rantai juga dan dinamakan dengan Rantai Garis. Jadi Garis Lyang melalui titik $a$ dan $b$ yang dinotasikan dengan $L=\overleftrightarrow{a b}$ dapat dipandang sebagai ruang topologi yang terturut total (rantai) serta memiliki struktur aljabarik berupa lapangan.

\section{DAFTAR PUSTAKA}

Bartle. R G, Sherbert. D R, (2001), Introduction to Real Analysis: Fourt Edition, John Wiley \& Spns, Inc.

Fraleigh, (1976), A First Course in Abstract Algebra: Second Edition, Addison-Wesley Publishing Company.

Gratzer G, (2010), Lattice Theory: Foundation, Birkhauser.

Hirali S, Vasudeva H L, (2006), Metric Spaces, Springer-Verlag, London.

Umble R N, Han Z, (2015), Transformational Plane Geometry, CRC Press Taylor \& Francis Group. 